\title{
ESL and EFL, Same or \\ Different? - The Question of \\ Professional Roles ${ }^{1}$
}

John Sivell

It is readily agreed that appropriate teaching methods and classroom materials can vary widely between ESL (for instance in Anglophone Canada) and EFL (in a nonAnglophone environment abroad). However, this article suggests that additional changes between the two domains also exist: ESL instructors moving into EFL overseas will often find their role as languageteaching professionals considerably modi- fied, in terms of their politico-cultural impact, their professional prominence, and their psychological security. Adaptation to such changes - both for maximized effectiveness and satisfaction abroad, and for greatest long-term growth after returning home- - depends on clear-sighted expectation and comprehension of the demands of these challenging but rewarding new experiences.

The question - ESL and EFL, same or different?-is well worth asking in a variety of circumstances, one of the most urgent being that of ESL teachers planning a period of service abroad. To what extent will ESL experience at home prepare instructors for $\mathrm{E} F \mathrm{~L}$ work in a nonAnglophone setting outside Canada? Naturally, a central concern is the pedagogical effectiveness that freshly converted teachers may expect to have in their new EFL endeavours. This issue, which must preoccupy conscientious ESL teachers embarking on an assignment overseas, can be and often is examined primarily by reference to the similar or different sociocultural dimensions of student needs and of appropriate teaching practices in each context (e.g. Brown, 1980, pp. 130-1). However, there is a further aspect of the same basic ESL/EFL question, rather less familiar but equally important: how does the professional role of ESL teachers compare to that of their EFL counterparts?

This consideration is particularly significant in view of the social dislocation and even downright homesickness likely to be experienced from time to time by teachers practising abroad. There is little doubt that (if available) a firm sense of maintaining one's professional identity and usefulness - no matter what other elements of day-to-day life may change - can be invaluable in helping adapt to an unfamiliar environment. But the question remains: are the professional roles similar? 
It is reassuring to reflect that despite changes in countless other domains, ESL teachers working in EFL abroad will at least to some extent continue to feel comfortable and useful in professional roles that by and large they may expect to recognize from their home experience: they will be instructors guiding classes of lively if at times fractious students, and also colleagues sharing the ups and downs of participation in an educational institution. These are facets of a familiar professional role which may appear to vary from the ESL situation at home only superficially; nonetheless, it is not helpful to exaggerate one's confidence in this continuity, because certain details of the total picture are very likely to manifest themselves in thoroughly unexpected guises.

Thus, I suggest that ESL experience does not entirely prepare one for EFL work, and that teachers making the shift must be ready to accept a number of quite significant adjustments regarding their new professional role. Certain general continuities will, of course, exist; additionally, it is important to recognize that any temporary strains will definitely be worth-while, if for no other reason than that EFL experience abroad can enormously enrich the sensitivity and effectiveness of teachers returning to the ESL classroom in Canada. Still, ESL teachers contemplating a stay overseas should expect to face challenges no less demanding than rewarding. A number of these challenges relate to the ESL/EFL teacher's professional role, and may be outlined as follows:

\section{POLITICO-CULTURAL ASPECTS OF THE EFL TEACHER'S ROLE}

Although not always the case, it is very often true that EFL teachers working abroad are employed directly or indirectly by the host government. This is the case, for example, with instructors teaching in the university or school system; it frequently also applies to those working through international co-operation agencies like CUSO or the British Council, or through multinational corporations (for instance, aviation, communication and construction groups often have EFL training services for technicians as part of their contracts with host governments). Consequently, EFL instructors not unusually find themselves involved in at least the implementation if not the actual development of national language-training policy, or even of teacher-training and educational policy in general.

As a result, Richards (1978) may in fact rather understate the case when he observes that the seemingly apolitical Applied Linguistics profession touches on issues with "important implications for educational policy" that "may even have political overtones" (p. 14). ESL specialists working 
abroad in EFL do not have to be training military, police or governmental personnel-common enough examples - for their work to have a political or more broadly cultural dimension. It is widely recognized that a developing nation planning industrialization will need to create a workforce prepared to accept the time constraints implied by factory employment; similarly, such a nation will probably wish to encourage a generation of learners who espouse new - and, to many, very foreignseeming - attitudes to training or education. Of course, these new values are not often taught explicitly, but they remain extremely important. For instance, my experience in North Africa and the Middle East, in both university and industrial settings, suggests numerous ways in which assumptions about the "best" work habits can underlie the EFL subject matter we teach. Most immediately, one may consider the real or imagined obsession of Western instructors with individual work and assessment (including strict observance of due dates for assignments, and of proctoring for tests), and with the assignment of grades according to performance alone, preoccupations often enough purported to be characteristically Western rejections of any tendency to allow social status or familial connections - or above all, personal favours to the instructor! to influence scores. On balance, it is perhaps fair to assert that although frequently more formal in social terms, many non-Western classrooms are comparatively easy-going as regards application of the letter of the academic law: we may find this pleasingly humane, or infuriatingly unprofessional, but in any case we may well be inclined (and enjoined) to substitute something more stereotypically "Western" in tone.

Such intervention is likely to be plain to the teacher, but other less obvious - though perhaps more significant - cultural (and ultimately political) strains will probably be created without our even being aware of them. An emphasis on regular homework assignments, for instance, will upset domestic arrangements in homes with little or no space for private work, and where-moreover-a family member's retreat into study can imply a rejection of the social structure of the group. A stress on rigorously critical examination of the most up-to-date published data on any subject will shake the foundations of societies with traditional respect for the oldest (usually religious) texts, and for the unchallenged word of elders. Equal education or training of both sexes, with the possibility that some women may outstrip some men, may be similarly unsettling. And on a more institutional level, the creation of a new cursus honorum, through education or training rather than through the traditional path of small business (typically controlled by a wealthy but nontechnocratic middle class), is another potentially very disruptive change. While EFL teachers may not precisely originate changes of this kind, they are almost certain to 
be in the vanguard of those effecting them.

This is not, of course, to suggest that ESL teaching at home has no politico-cultural dimension. But, while teaching in Canada, possibly helping newcomers or visa students adapt to life here, ESL instructors may feel on the whole so well in agreement with the utility and necessity of the underlying habits and assumptions they promote as to be barely conscious of the way in which, as Halls (1976) comments, "modern educational systems have developed as instruments for the transmission, diffusion and enlargement of a nation's cultural patrimony" within the framework of an almost universal desire to "use education ... to achieve national purposes" (p. 21). By contrast, in an unfamiliar political, social and cultural order abroad, where often necessarily impatient developmental planning may make the entire process unexpectedly visible, EFL teachers are likely to have this aspect of their professional roles brought to their attention with a vividness never previously imagined.

Above all, this phenomenon is apparent when preparing students for study overseas in Anglophone colleges or universities, or for work with Anglophone advisors in national industries, because in these circumstances EFL teachers are regularly encouraged to instruct their students not only in EFL itself, but also in "study skills"... a vague mandate that seems to include everything from library access or bibliographic methods, to Westernized concepts of time use, scholarly individualism, and career goals. All this implies a massive hidden curriculum of personal as well as academic values, implemented by-although not always formulated in cooperation with - EFL teachers from abroad. If the pace or direction of government planning is out of step with student aspirations, the result can sometimes be a lengthy, extremely delicate, and not always overly profitable tightrope-walking act, during which the EFL teacher attempts to reconcile students needs and institutional demands. For instance, teaching materials and test standards may bear little relationship to the current real level of ability of the learners. Or, the assignment of students to subject specializations may be carried out in ways that more exactly reflect national planning needs than student preferences (or aptitudes). Although the problem rarely becomes totally unmanageable, in extreme cases EFL teachers may indeed feel trapped in the uncomfortable role of apologists for a committee of policy-makers they do not fully support, to a study body they do not totally understand. Somehow, a viable compromise must be reached; striving towards it can be both exciting and rewarding, as well as very trying, but in any case it will highlight a facet of the EFL teacher's professional role abroad that is far less salient in the ESL context at home. 


\section{PROFESSIONAL PROMINENCE}

ESL is a comparatively new, almost an upstart discipline. Additionally, students served by ESL classes are most often outside the mainstream in one way or another: newly arrived immigrants, probably not yet employed and certainly without social or political clout; visa students at high school, for whom English is strictly a practical necessity on the way to their real academic goals; or ESL students at university, whose language courses are almost always non-credit and whose teachers in the main are untenured and of low academic rank. These circumstances normally lead - as hardly needs saying - to a relatively "marginal" professional status for those of us engaged in ESL in Canada. We do of course have our local and national professional bodies, our conferences, our journals, and above all our individual devotion and professionalism... nevertheless, when the general public (or the administrators of educational institutions) envisage the profile of a "typical" teacher, it is hardly the ESL instructor who springs to mind! Consequently, ESL teachers themselves may view their professional role as one that - while definitely not lacking genuine merit - is all the same comparatively low-key and, frankly, uninfluential.

However, this low profile is likely to cease when teachers move from ESL to EFL. EFL teachers abroad, especially in developing countries, frequently have more or less the status of visiting international experts whose experience and up-to-date training are much to be respected, and who are very definitely admired by their local colleagues. In my own experience, this increased prominence appears to stem from a number of causes. For one thing, even a relatively low-ranking EFL staff member may benefit from what can seem to local teachers to be astonishingly easy access to much higher-ranking members of the institution. Partly, this can result from an institution's willingness to welcome new teachers from overseas by having them greeted by leading officials; partly, it may simply be a function of visitors' not knowing (and hence not obeying) the host culture's conventions about who should or should not be approached for aid or information. Additionally, EFL teachers assigned tasks like doing a needs analysis for an ESP project, or designing a teacher-training scheme, will perforce seem to move with unusual ease within the structure of the industrial or academic organization under study. And finally, of course, EFL departments tend to be staffed by a high proportion of Anglophone Westerners, so that the atmosphere may be more informal and egalitarian than in neighbouring sections of the same institution, with fewer visible marks of differing high or low status. All together, these 
factors quite often cast the EFL teacher in the role of a remarkably independent, self-confident, and respected professional, with considerably higher status than the same individual might possess in an ESL context at home.

In a comment relevant to this issue of the typically rather high standing of EFL teachers abroad, Patrie (1984) - with the specific example of China in mind-outlines an ironic dilemma besetting those responsible for candidate placement: while younger and perhaps less qualified teachers may have most freedom to accept the opportunity of a posting overseas, more seasoned instructors with "appropriate training and experience" to meet the exacting standards set by many host countries will often hesitate to leave hard-won positions in Canada (p. 94). And it should be recognized that even when official requirements do not interfere, EFL abroad is probably not the best environment in which for beginners to gain their earliest experience. The heightened professional prominence likely to await these teachers promises more than a welcome increase in respect; it entails a concommitant increase in responsibility. Conscientious ESL teachers moving into EFL outside Canada might well themselves feel that anything less than the most solid preparation would be, in Patrie's terms, "woefully inadequate" (p. 96).

To move comfortably into the new role, professional training in ESL (or specifically in EFL) and a fair amount of teaching experience are essential. Without such preparation, EFL teachers may well find it all but impossible to meet expectations and to accomplish the valuable work that should be done. Plainly, these strictures depend to an extent on the precise context of teaching. My experience in France suggests not only that EFL teachers in Europe can anticipate guidance and infrastructure support (materials, classrooms, hardware) similar to what ESL teachers in Canada might expect, but also that they will probably not experience the pressures - or advantages - of much increased professional prominence. However, EFL teachers in developing countries will often be very much alone while dealing with the responsibilities of their frequently extremely demanding roles. In these circumstances, confidence in one's professional training and experience is a must.

\section{PSYCHOLOGICAL DIMENSIONS OF THE EFL ROLE}

ESL teachers working at home in Canada are in a comparatively strong position compared to their students, especially if these are visa students or new immigrants. We are living in our own society, and co-operating with English-speaking colleagues who are likely more or less to share our views of education. EFL teachers abroad, by contrast, in many respects are in a 
situation similar to that of our more insecure students here: they are outsiders, probably welcomed but still obliged to confront a long series of sometimes embarrassing or frustrating cultural surprises. Apart from such obvious sources of inconvenience-or adventure! - as significant changes in the climate, in the type and marketing of food, and of course in the language, there will be many other causes for genuine insecurity that are discussed far less often. For instance, freshly arrived EFL teachers will have to establish contacts with new doctors and dentists, arrange schooling for their children, cope with the bureaucracy of residence permits, come to terms with the rival claims of local and expatriate social groups, and so on. It can truly be said, then, that EFL instructors tend to experience first-hand much of the psychological strain felt by the ESL clientele they may later return to teach in Canada. And these factors all contribute to the creation of a much-altered psychological role for ESL professionals working in EFL abroad. Moreover, we can isolate two particularly classroom-specific instances of such change, regarding attitudes to methodological innovation, and "ego states" as described by Stevick (1976).

Although, as already suggested, EFL teachers abroad are frequently called upon as resource people, there may be clear limits to the ways in which this role can actually be fulfilled. Especially in the developing world where there is often a more conservative - and, many would protest, a more measured - respect for old, established approaches than we express in the West, our most popular new methods or materials will commonly be required to make their way not so much by the force of theoretical enthusiasm, as by the effect of demonstrated satisfactoriness in the roughand-tumble reality of the classroom. And as visitors, EFL instructors can hardly expect simply to impose their pet methods or theories.

It is no surprise that EFL students resemble learners of any other subject: they approach their classes with firm expectations as to what constitute worthwhile methods and activities. Indeed, because language learning is such an affective process, these expectations may be more than usually rigid. Moreover, adults or young adults are likely to articulate their preconceptions very clearly, and to have a distinct-and often well-founded - sense of their own purposes and requirements as learners. Consequently if, for instance, students have traditionally expected grammar-translation or audio-lingual approaches to EFL, it may be difficult to gain their acceptance of newer and necessarily unfamiliar communicative methods or materials without an initial campaign to teach them how to work with the new approach, and to win their trust in its effectiveness. While teaching in Iran, Saudi Arabia and Morocco, I have observed - and at least sometimes managed to overcome - this kind of 
understandable student skepticism about methodological innovation. Theoretically desirable changes in approach will not always "sell themselves" (Sivell, 1983). The need for cautious patience might seem obvious, but it is easily overlooked by disoriented teachers already suffering from countless other delays and irritations.

Also, although typically hired for their training in innovative methods, EFL teachers abroad may well discover that restrictions on equipment, maintenance or materials make it virtually impossible to put all their relevant knowledge into effect, no matter how willingly received it apparently would be. For example, if all available reading books are heavy on grammatical exploitation exercises but light on interpretive work, with very little textual volume for the practice of rapid silent reading, even instructors committed to a focus on reading as a specific skill in itself may feel rather helplessly forced to transform so-called EFL reading classes into undesirable de facto extensions of the grammar component of the course ... as a result, whatever such teachers' initial convictions and intentions, frustrating circumstances may unexpectedy oblige them to adopt very much the approach they originally viewed themselves as replacing!

Comparable strains may be created by reticence on the part of EFL colleagues. Often, hesitation that a newcomer might rashly attribute to the weight of uncritical tradition is in fact the result of lengthy experience with reactions from both students and the powers that be. A good illustration is a series of team-teaching sessions at a middle school in South-West Iran, where one student and I were attempting to introduce pair work as a technique to overcome the large size of the EFL class. We anticipated and overcame the first wave of surprised nervousness from the learners, who had never experienced anything other than a thoroughly teacher-centered classroom, but we still had difficulties with the plainly unsympathetic-even hostile - response of most other teachers in the school. Then, the headmistress visited our classroom, and did more than merely say she supported our efforts: she actually sat down as part of one of the pairs and did the lesson with the pupils! Only from that point were other language teachers sure that this innovation was not only academically but also administratively acceptable in the school. This success depended on both an open-minded administrator, and a shrewd and rather courageous local team-teacher. And not surprisingly, the happy convergence of such factors seems more or less universally important; for example, Allen has outlined generally similar considerations for EFL work in China (Allen et al., 1985).

ESL teachers moving into EFL overseas must realize that circumstances propitious for innovation are not always ready-made; often, despite our natural impatience to share our expertise, restraint will be necessary 
until the correct situation arises or can be created. Wise EFL teachers must delicately balance a knowledge of the latest pedagogical procedures, against a sense of the local infrastructure and educational climate. What in home terms might well be "wrong" can be "right" in other circumstances. Thus, as in ESL but with much increased urgency, in EFL we must understand Wilkins' $(1974$, p. 86$)$ point that even theoretically “ 'good' methods" can fail when applied insensitively. EFL teachers abroad may well be leaders, but they are also outsiders who must tactfully observe, adjust, and suggest. This can be a difficult role for energetic Westerntrained professionals.

A second major issue of psychological concern is that, as outsiders, EFL professionals may find it useful or even essential to modify the nature of their personal relationship with their students. Despite being, in one sense, comparatively exalted visiting experts, they will - as outlined above - for a considerable time remain disadvantaged by their ignorance of the conventions ruling life both inside and outside the classroom. Students, by contrast, will be experts in these matters. Consequently, even teachers disinclined to do so when working at home in ESL may find it desirable or necessary to move from what Stevick terms a parent-child ego state relationship with students $(1976$, p. 66-8), with considerable dominance for the instructor, to a more equal relationship of the adult-adult sort (p. 132). The EFL teacher may need student co-operation and even support in ways and to an extent unimagined while at home in an ESL role. Relatively trivial aspects of this dependence include the possible difficulty for a new teacher of fathoming the infrastructure of services (e.g. sources of chalk and other materials, copies and so forth), or the inability to communicate with colleagues or other employees outside the EFL department (students may become invaluable translators). More significant is the way in which visiting teachers will probably rely on discussion with students for extremely useful and often quite personal advice on social and recreational possibilities, housing, prices, and so forth. And in many cases conversations will eventually broach political and cultural questions that can mark a visitor's thinking more or less permanently.

Of course, if one objective of going abroad is to learn how it feels to live in another culture, we ought not to be surprised to find that our students have become models for our behaviour, and are to quite an extent our equals. But the resulting quasi-reversal of psychological roles can be just as challenging as can be the sudden need for unexpected caution and flexibility with regard to our most-trusted methodological innovations. As with adjustments in the new EFL teacher's politico-cultural and professional roles, the magnitude of these changes should not be underestimated. Whether the addition of such new dimensions to the teacher's 
evolving professional identity will be burdensome or enriching is largely a matter of preparation.

\section{ENDNOTE}

1. This article is a revised version of a presentation at the TESL-Canada meeting in November 1985 in Toronto.

\section{REFERENCES}

Allen, W., D. Cooke, D. Phillips \& J. Sivell. (1985). ESL and EFL, same or different? Panel Discussion at TESL Canada Converence, Toronto, November 1985.

Brown, R. (1980). Principles of Language Learning and Teaching. Englewood Cliffs, NJ: Prentice-Hall.

Halls, W. (1976). Education, Culture and Politics in Modern France. Oxford: Pergamon.

Patrie, J. (1984). Foreign expertise in the Chinese context. TESL Canada Journal, I, ii, 93-6.

Richards, J., ed. (1978). Understanding Second and Foreign Language Learning: Issues and Approaches. Rowley, Mass.: Newbury House.

Sivell, J. (1983). A realistic view: functions of another language. Mc Gill Journal of Education, XVIII, i, 64-9.

Stevick, E. (1976). Memory, Meaning and Method: Some Psychological Perspectives on Language Learning. Rowley, Mass.: Newbury House.

Wilkins, D. (1974). Second Language Learning and Teaching. London: Arnold.

\section{THE AUTHOR}

John Sivell is Associate Professor of TESL methodology in the Centre for English Language Programs, Brock University. His special interests are Reading and Discourse Analysis. He has taught - freelance, and with universities and language institutes - in Canada, England, France, Morocco, Saudi Arabia and Iran. In 1983 he returned to Ontario after 14 years of work and study abroad. 